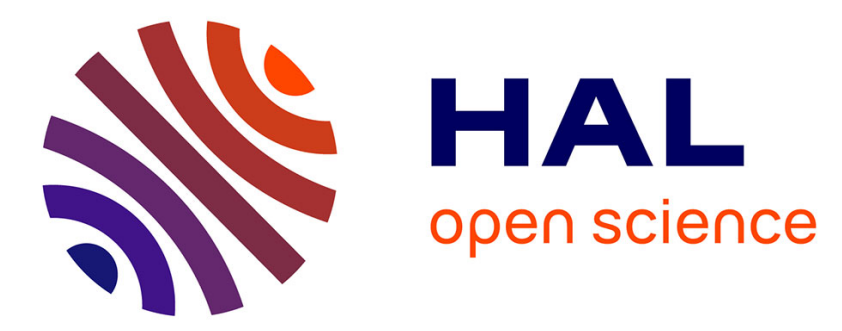

\title{
Emotirob: from understanding to cognitive interaction
}

Amel Achour, Marc Le Tallec, Sébastien Saint-Aimé, Brigitte Le Pévédic, Jeanne Villaneau, Jean-Yves Antoine, Dominique Duhaut

\section{To cite this version:}

Amel Achour, Marc Le Tallec, Sébastien Saint-Aimé, Brigitte Le Pévédic, Jeanne Villaneau, et al.. Emotirob: from understanding to cognitive interaction. In 2008 IEEE International Conference on Mechatronics and Automation - ICMA 2008, Aug 2008, Takamutsu, Kagawa, Japan. pp.369-374, 10.1109/ICMA.2008.4798782 . hal-00507537

\section{HAL Id: hal-00507537 https://hal.science/hal-00507537}

Submitted on $30 \mathrm{Jul} 2010$

HAL is a multi-disciplinary open access archive for the deposit and dissemination of scientific research documents, whether they are published or not. The documents may come from teaching and research institutions in France or abroad, or from public or private research centers.
L'archive ouverte pluridisciplinaire HAL, est destinée au dépôt et à la diffusion de documents scientifiques de niveau recherche, publiés ou non, émanant des établissements d'enseignement et de recherche français ou étrangers, des laboratoires publics ou privés. 


\title{
EmotiRob: from understanding to cognitive interaction
}

\author{
Amel Achour, Marc Le Tallec, Sébastien Saint-Aimé, Brigitte Le Pévédic, \\ Jeanne Villaneau, Jean-Yves Antoine, and Dominique Duhaut
}

\begin{abstract}
The ANR project EmotiRob aims at conceiving and carrying out a soft toy robot which can interact emotionally and cognitively with handicapped and fragile children. However the project MAPH (Active Media For the Handicap) which is an extension of EmotiRob extends the cognitive abilities of the robot so as to implement linguistic interaction with the child. This article presents our work for both projects: speech understanding, emotional interaction, cognitive interaction.
\end{abstract}

\section{INTRODUCTION}

A new stake for robotics is the domain of companion robots which execute complex tasks and offer an behavior enrichment through their interaction with human beings.

The objective of this project is to design an autonomous and "reactive" stuffed robot which might provide some comfort to vulnerable children (for example, children undergoing long-term hospitalization). Previous experiments have already shown the contribution of robot companions in this type of situation. Compared to these studies, one of the specificities of our robot is to be able to react to the behavior of the child by simulating emotions through body movements, facial expressions and small simple sounds.

This project, centered on detection and simulation of emotions, lies at the interface of robotics and humanmachine communication and vision. It particularly raises several interesting scientific problems:

- "understanding" the language of a child who talks to his stuffed animal (in this case, the robot) and detecting their emotional state,

- equipping the robot with a pertinent capacity of emotional reactions, and making these emotions intelligible through the robot's expression,

- evaluating the contribution of this interaction: how does one measure the comfort of a child, etc.

Manuscript received May 31, 2008. This work was supported in part by the regional council of Martinique, for the development of the emotional synthesis, the regional council of Bretagne for the cognitive interaction, and the ANR for the language comprehension and construction of the robot.

Amel Achour is with the Valoria Laboratory of the University of Bretagne Sud, Vannes, France (phone: +33 297874545; fax: +33 297017279; e-mail: amel.achour@univ-ubs.fr).

Marc Letallec is with the Computer Science Lab. (LI) of the U. François Rabelais of Tours, France (e-mail: marc.le-tallec@etu.univ-tours.fr).

Sébastien Saint-Aimé is with the Valoria Laboratory of the University of Bretagne Sud, Vannes, France (phone: +33 297017261; fax: +33 297017279; e-mail: sebastien.saint-aime@univ-ubs.fr).

Dominique Duhaut is with the Valoria Laboratory of the University of Bretagne Sud, Vannes, France (phone: +33 297617206; fax: +33 297017279; e-mail: dominique.duhaut@univ-ubs.fr).

\section{A. Synoptic}

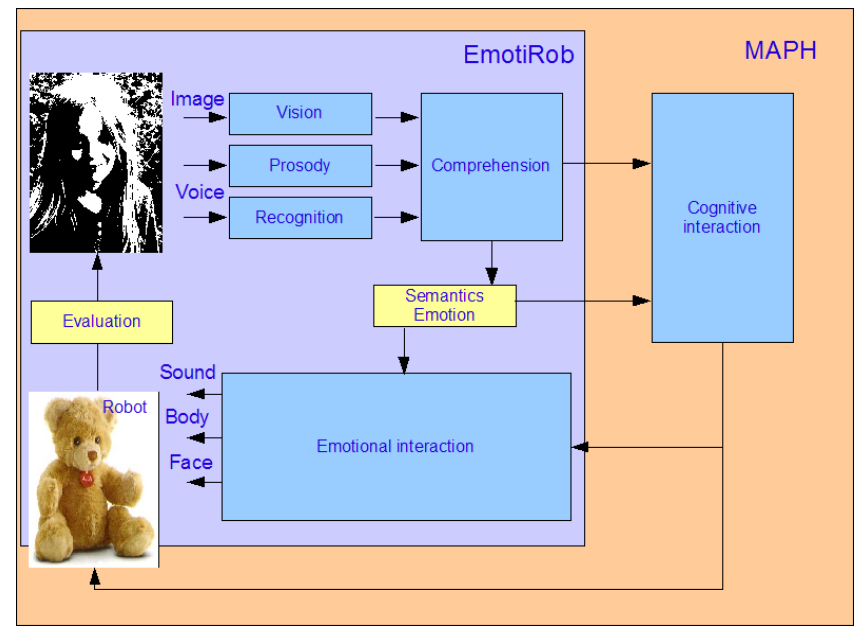

Fig. 1. Project synopsis

Fig. 1 shows our synopsis, giving the different modules which will forward good development of our project:

- In our entry understanding module is the information of processing prosody, video, as well as voice recognition. These factors will enable us to gather the utterances of the child, as well as his emotional state.

- Once the entries are processed, this information will be forwarded to the emotional interaction module via a semantics emotional structure.

- A portion of the information handled by the entry module will allow the cognitive interaction module to determine an appropriate reaction to the behavior and discourse of the child.

- The output will transcribe the interaction and emotion of the robot through small sounds, body movements and facial expressions.

\section{UNDERSTANDING SYSTEM}

In the EmotiRob project, the understanding system has to handle a child's language and detect his emotional state. To do this, we have decided to use an older understanding system, LOGUS, and to adapt it.

\section{A. Logus}

The LOGUS system [1] proceeds in three main stages, as indicated in Figure 1, to transform the statement of a logical formula. These three stages are the lemmatisation, the segmentation, and the creation of the semantic links. 
a)

Lemmatisation

This first stage consists in replacing every word of the statement by a translation compound of a triplet including the syntactic label, the semantic label, and the semantic representation contained in a lexicon. If a word possesses several definitions, they are then all kept for the following stages.

In the Emotirob project, we have to create the new lexicon.

\section{b) Chunking}

Studies of repairs in French have shown that they preserve minimal syntactic structures: in $70 \%$ of the speech repairs of prepositional syntagms, the syntagm is resumed as a whole [2]: "vers le vers la station" ("at the at the station"). According to these results, chunking seems possible to parse spoken language.

Nevertheless, the evaluation of a LOGUS prototype has shown that chunking is effective provided that chunks are very short. More precisely, errors made at the speech recognition level make it dangerous to link objects or properties after purely syntactic criteria, without checking these links in the ontology. Therefore the chunks used in LOGUS, called minimal chunks, include only one content word. General principle consists in linking function words to the near content word.

The formalism used for chunk parsing is Categorial Grammars of $\mathrm{AB}$ type, whose rules are generalized to constituent triplet. Function words have definitions where syntactic category and semantic role are fractional. In these definitions, semantic translation is an abstraction (in the $\lambda$ term meaning). The semantic translation of the result triplet is achieved by applying this abstraction to the semantic translation of the un-fractional triplet.

\section{c) Semantic dependencies}

The limited scope of the domain application is captured in a domain ontology. It aims at specifying how objects and properties can be compound. Despite the use of this domain dependent ontology, the system is expected to be generic. To achieve this, the ontology is built with generic predicates, whose domain objects and domain properties are the arguments.

The aim of this second phase is to find semantically most significant constituents, and to link other constituents to them under the control of the ontology. For instance, in the system LOGUS, if a user asks: " I want to reserve a hotel for two persons unless $100 € "$ ", it is the semantic knowledge which is going to allow us to understand the sense of the statement. Knowing that a hotel is composed of rooms and that a room has for properties a price, we are going to be able to join every segment of the sentence to understand that the speaker wishes to reserve a double room for a price inferior to $100 €$.

For Emotirob project, we have to recreate a new ontology. We have not ambition to create a system able to treat all domains, with any person. We know that to represent all the knowledge of the world is an impossible thing. To make it for a restricted domain is already a difficult thing, but we think that by choosing a public of children, we are going to restrict the vocabulary enough to manage to simplify the necessary semantic knowledge.

\section{B. Adaptation of Logus}

The first operation was to create a new lexicon with the words that children could use. We, therefore, obtained information on the language of the children from available data, which is Novlex [3], Manulex [4] and a study by Dominique Bassano. This lexicon consists of about 8000 lemmas all total which will represent the all of the vocabulary the robot will be able to understand.

The module of understanding is based on the same architecture as the LOGUS system, as well as three stages. The choice of the words of the lexicon being made, it is necessary to add all the translations for the stage of lemmatisation. It is necessary to rewrite, as in the LOGUS system, the syntactical labels, the semantic labels and the semantic representation of every entry. Syntactic structure of sentences that should remain appreciably identical, and the LOGUS system having shown its efficiency, the syntactical labels were preserved as in LOGUS. The rest, however, is to be completely revised. The problem is that in going on to a wider domain, the number of objects strongly increases.

At first, the idea is not to create one ontology, but much ontology in domains very known by children, and to connect each to others (for example animals, school, family...). It will be necessary to verify, notably in the corpus, how the children approach the various domains to choose what the indispensable domains for our knowledge are.

For the moment, as we have many semantic labels, the first work consisted in classifying all our objects in subsections to create major categories, for example, animals, people, places, food ... These categories are then divided up into sub-categories. For example, we classified animals into three categories: the familiar animals (that can live in the home), the close animals (that the children are used to seeing) and the distant animals. These successive divisions allow us first to decrease the number of labels to be treated and to look for the properties common to the objects of the same category.

This works is at the beginning and we have to continue to create ontology. After we will have to search how detecting emotions of children.

\section{EMOTION SYNTHESIS}

Emotion synthesis is an artificial reproduction of the way that human beings express their emotions in a social human context. Being able to express emotions is a way for a robot to communicate with a human. Without emotional expressions, users may interpret the interaction as a lack of interest from the robot and will then stop communication.

Robots (like Kismet, Paro, Necoro, Aibo, Asimo, etc.) 
capable of social interaction are then characterized by their ability to have behavior close to that of humans.

Emotion is an expression of one's internal state. Joy and fear are different emotional states and can be characterized with physiological and psychological criteria. Through emotion synthesis, those criteria are imitated to bring about a believable artificial emotion. This artificial emotion is then used to reinforce communication: verbal or non verbal.

\section{A. Facial Animation for EmotiRob}

We have presented research on the question "how can an emotion be simply drawn?" In this evaluation, based on a specific set of faces having different degrees of freedom [13], it can be noticed that the one with the highest score is not the most complex one, as in Fig. 2.

After defining the face for our robot it will now be necessary to give it dynamics. Knowing that we are primarily working with emotional experiences [18], the first task will be to define the emotions felt for each of these experiences. These emotions will be classified and organized into a hierarchy according to several existing models [14] [15] [16] [17] [18]. This categorization allows us to choose the best method to go from one emotion to another.

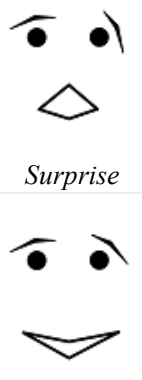

Joy

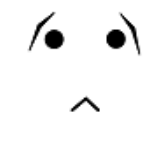

Sadness

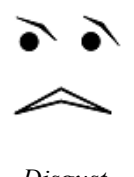

Disgust

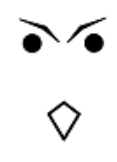

Anger

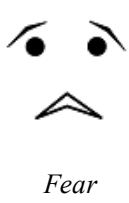

Fig 2. Face and examples of expressions for the robot

\section{Mechanics of the Robot}

The mechanics of EmotiRob can be separated into three modules. The first module is the head. It contains all of the motors in order to set the eyebrows, jaws and corners of the mouth into motion. The second module is the neck, it contains two motors. The third module is the pelvis which also contains two motors

\section{A. Activation of the eyebrows}

The eyebrows are operated independently by two servomotors type BMS 303 (BlueBird). The actuator results in a rod-crank system guided by a groove in the structure. The groove is straight for the moment in Fig. 3, but it might also be curved to enhance the expression of the robot.

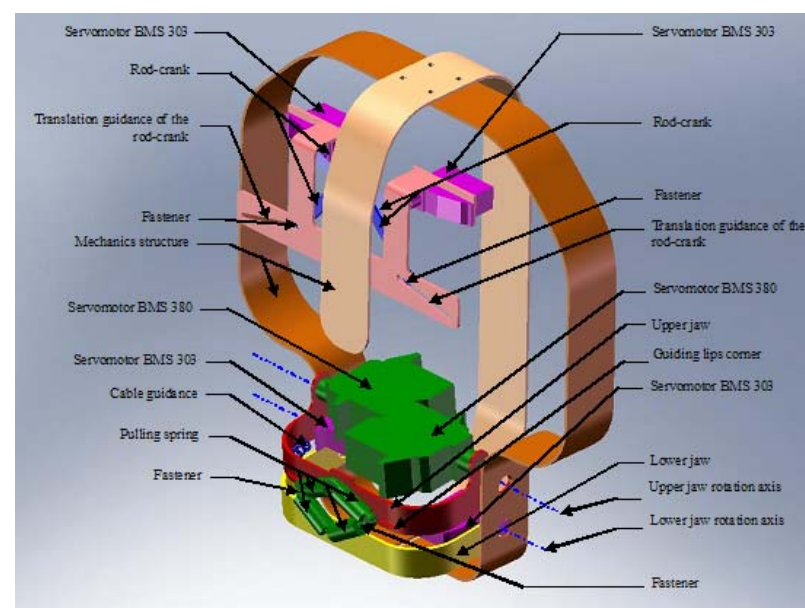

Fig 3. Head of EmotiRob

\section{B. Activation of the jaws}

The upper and lower jaws are independent from each other. Each is driven by a servo-motor type BMS 303 (BlueBird). The range of motion of the jaw should not be too large.

\section{Activation of the lips}

The corners of the lips are also independent from each other to increase the possibilities of facial expressions. Each is operated by a servo-type BMS 380 (BlueBird), which pull a cable on which a two-spring traction (upper and lower) is fixed. These springs allow for the various lengths of the "lips" while playing the role of tendon from the mouth. The cables pass through rings along the upper jaw. This will transform the movement of rotation of the actuator movement in translation along the jaw. The BMS 380 servomotors are sized to be able to stretch the springs.

\section{Neck and pelvis mechanics}

Both modules are treated the same for reasons of ease of implementation and since their features are the same. This module must be disengaged: the force on the rotation should not damage the motors. With force rotation, the compression spring shrinks as a result of a force that is applied along the axis of rotation. This contraction disassociates (disengagement) both toothed surfaces and thus the rotation takes place freely without damaging the mechanical actuator. The principle is the same for both axes. Once there is no more force on the rotation, the compression spring applies an effort (clutch), which goes put in touch toothed surfaces. 


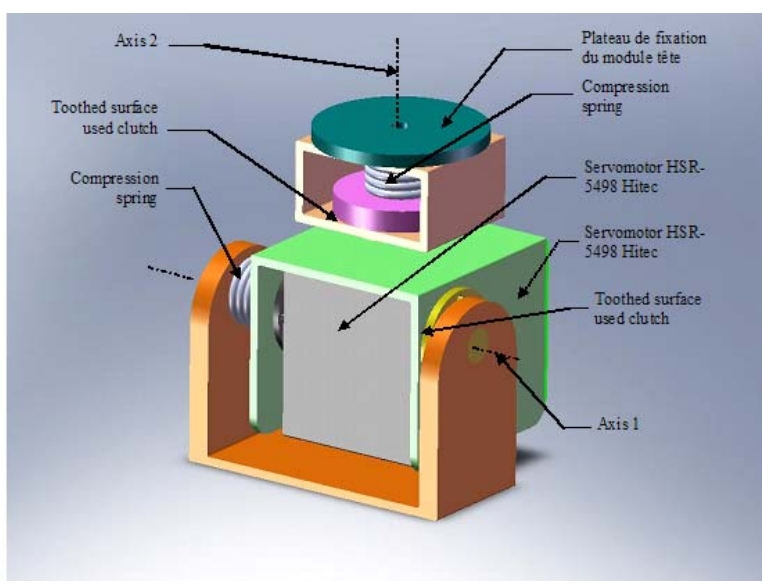

Fig 4. Neck and pelvis module

\section{Cognitive InTERACtion}

The Cognitive interaction module corresponds to a part of the MAPH project (Média Actif Pour le Handicap) which is related to the EmotiRob project. It aims at extending the reaction capacities of the robot so that it could maintain a "conversation" in a natural language with the child. The purpose of this work, indeed, is to build a linguistic and cognitive interaction module between the child and the robot by generating new sentences to carry out a "conversation" with the child. The understanding module presented below supplies inputs for the cognitive interaction. The sentences generated by the robot depend on the emotional states of both robot and child.

Carrying on a "natural" conversation with a machine on a non constrained subject seems to be very difficult and even impossible [23] as we cannot model world knowledge right now. By restricting the field of the conversation and choosing a well-defined subject, the use of natural language in order to carry a "dialogue" becomes feasible but still very difficult. Some existing systems of human-machine dialogue that we can quote here are COALA ${ }^{1}$ which is a system for documentary assistance in a town media library, CMU Communicator $^{2}$ which is realized by Carnegie Mellon University, and serves as a tourist guide. Problems that come up against the conception and the realization of humanmachine dialogue systems are essentially oral language recognition and understanding [21], real time conversation constraint and finally, speaking with the machine must not require learning from the user [22].

Regarding our work, we are implementing a generic human-machine dialogue system dedicated to young children. We are dealing with vocabulary covering the child's entire surroundings. This is quite problematic as we have a non-restricted conversation domain. However, limiting the users of our system to young children makes the vocabulary we are interested in quite restricted. Under this condition, producing a dialogue between the child and the robot is conceivable.

\footnotetext{
${ }^{1}$ http://www-ic2.univ-lemans.fr/ lemeunie/these/node35.htm

${ }^{2}$ http://www.speech.cs.cmu.edu/Communicator/
}

In this work, we used a corpus elaborated by means of the DLPF tool, realized by D. Bassano, F. Labrell, C. Champaud, F. Lemétayer and P. Bonnet [19] and used to estimate the development of production language of French children whose age is between two and five. The corpus counts a little less than 1500 words including nouns, verbs, adjectives, adverbs, onomatopoeias and common expressions, articles and pronouns... among which we find all the common vocabulary that could be said by a 4-yearold child. The problem which arises is then how to model the conceptual world of a very young child. By studying the semantic relations which could exist between the different words of the corpus, we established a classification of the words or rather taxonomy according to not only objective but also emotional properties. Moreover, we tried to be in accordance with a child's way of thinking and perception of things. That is why we tried to validate our research with children and to verify if we have satisfied these constraints.

\section{A. Taxonomy creation and validation with children}

In order to calculate the coefficients of the semantic link between pairs of words, we start with classifying the corpus words in various classes and sub-classes according to their meanings. The figure below shows a small outline of the taxonomy that we obtained. The detail of the taxonomy is visible on the website of the EmotiRob project [24].

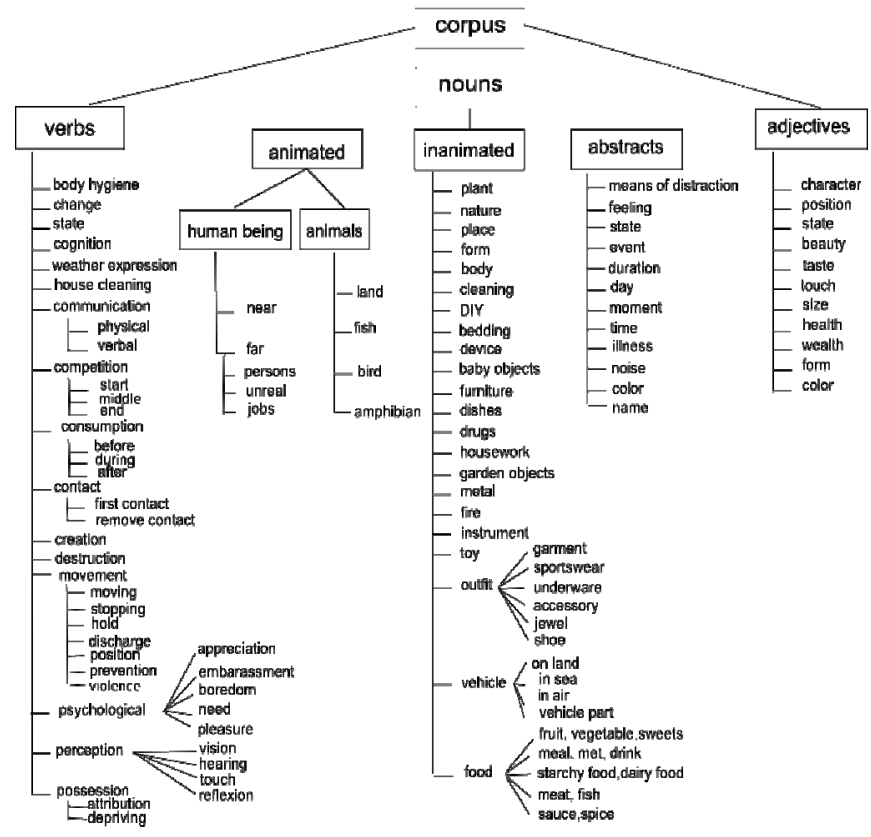

Fig 5. An outline of the taxonomy of children words

To validate the words taxonomy that we created, we thought of making a questionnaire and had children between the ages of 5 and 7 fill it out. According to Piaget [20] the children of the lower ages tend to fantasize and to say anything when they do not know the answer of the question or even when they are not sure of it. It is what Piaget called the "n'importequisme"3 phenomenon.

To implement the various questions and parts of the questionnaire, we used the test method, which is often

\footnotetext{
3 “whateverism »
} 
employed in the study of childhood beliefs. This method requires two essential conditions: the first one is that questions should be the same for all the subjects and asked in the same circumstances. The second condition requires that all the answers must be reported to the same evaluation scale. This method is more efficient if someone varies the questions and makes counter-suggestions. Thus, in our questionnaire we opted for various types of questions such as questions with multiple choices, tables to fill out, as well as searching for adequate solutions among a set of possible ones.

This questionnaire essentially concerns the animated beings that surround the children: human or animal, and with whom they can have more or less emotional links. The first part of the questionnaire was dedicated to human beings. At first, we asked the children to distinguish the characters we find around us from those who exist only in tales. And secondly, we asked them to reveal the different primary feelings which these characters evoke for them.

The second part was dedicated to animals and aimed at verifying their belonging to the different categories established in the taxonomy. The questionnaire was filled in by first-grade pupils from "Sainte Marie" elementary school in Lorient in France twice. After the counting of the answers, we noticed that, in the majority of the cases, the results are in accordance with the taxonomy and answer, indeed, our expectations. Nevertheless, certain results surprised us and made us modify the taxonomy. For example, according to $92 \%$ of the questioned children, "king" and "prince" characters do not exist in the real world and are only in tales and stories we tell them. "Father Christmas" belongs to the set of imaginary characters for only the half of the children, the other half consider him as a real person. $80 \%$ of children are "happy" when they see a "magician" and consider him as a "kind person". To many children, almost half, an "ostrich" and a "penguin" are not birds, and nearly $70 \%$ of them think that a "whale" is a fish.

\section{B. Calculation of semantic rapprochement coefficients}

Using the taxonomy, we defined and measured semantic rapprochement coefficient which exist between the corpus words. In what follows, we describe these coefficients, as well as the method used for calculation.

Rapprochement coefficient between two words having the same type: The set of common nouns was divided into three big classes, the class of animate, inanimate and abstracts. Each of these classes was afterward divided in several sub-categories, and so on. Here is the formula used to calculate the distance $\operatorname{Rapp}(N 1, N 2)$ between two common nouns $N 1$ and $N 2$ :

$$
\operatorname{Rapp}(\mathrm{N} 1, \mathrm{~N} 2)=\frac{\mathrm{C} 1 * \mathrm{R} 1(\mathrm{~N} 1, \mathrm{~N} 2)+\mathrm{C} 2 * \mathrm{R} 2(\mathrm{~N} 1, \mathrm{~N} 2)}{\mathrm{C} 1+\mathrm{C} 2}
$$

As can be noticed, the rapprochement coefficient between two common nouns is a weighted average between two coefficients, the first of which, $R 1(N 1, N 2)$, calculates the rapprochement between both words in the taxonomy, whereas the second evaluates their rapprochement regarding to their common properties number. We distinguished two types of properties: affective properties and objective ones. Each property was balanced with a weight measuring its importance in defining a certain set of words. $\mathrm{R} 2$ is then the weighted average of an affective rapprochement $\operatorname{Raff}(N 1, N 2)$ balanced by an affective coefficient $Q a$, and an objective rapprochement $\operatorname{Robj}(N 1, N 2)$ balanced by an objective coefficient $Q o$.

$$
\operatorname{Raff}(\mathrm{N} 1, \mathrm{~N} 2)=\frac{\text { nbr_prop_aff_com }(\mathrm{N} 1, \mathrm{~N} 2)}{\max \left(\mathrm{nbr} \_\right. \text {prop_aff(N1),nbr_prop_aff(N2)) }}
$$

$$
\begin{gathered}
\operatorname{Robj}(\mathrm{N} 1, \mathrm{~N} 2)=\frac{\text { nbr_prop_obj_com(N1, N2) }}{\max \left(\mathrm{nbr} \_\right. \text {prop_obj(N1), nbr_prop_obj(N2)) }} \\
\mathrm{R} 2(\mathrm{~N} 1, \mathrm{~N} 2)=\frac{\mathrm{Qa} * \operatorname{Raff}(\mathrm{N} 1, \mathrm{~N} 2)+\mathrm{Qo} * \operatorname{Robj}(\mathrm{N} 1, \mathrm{~N} 2)}{\mathrm{Qa}+\mathrm{Qo}}
\end{gathered}
$$

The rapprochement coefficients we obtained depend on the $Q a$ and Qo that we chose. For instance, "ladybug" and "louse" will be semantically close if Qo is bigger than Qa. Otherwise, they will be distant.

The semantic rapprochement between two verbs or two adjectives is calculated in the same way. However, for verbs, we take their respective types (intransitive, transitive or double transitive) and the taxonomic rapprochement between their subjects and respective complements into account. As for adjectives, we take the types of the subjects that could be applied to them into account.

Rapprochement between verb and noun, adjective and noun: We defined the rapprochement coefficient between noun and verb to measure the applicability of some verbs to a particular noun. For example, we can say that the verb "to bore" applies perfectly to an animate subject whereas if the same verb can be applied to a "chair", that is possible only in an artistic or a funny context. Also for adjectives, the rapprochement coefficient between noun and adjective measures rather the use of an adjective with a certain name in a particular speech context.

\section{Sentence generation}

The sentence generation model that we adopted works with simple input sentences such as (subject, adjective), (subject, intransitive verb), (subject, transitive verb, complement) or (subject, verb double transitive, complement1, complement2). At the present time, we have limited our choice to one type of sentence which is the affirmative sentences. Later, we intend to work on the acts of language and to introduce the interrogative, imperative sentences, etc. The generation module takes several parameters into account which describe the emotional state of the child, as well as the humor of the robot. First of all, it analyzes the input sentence so as to find the context that the speech is about. Secondly, it looks for words which represent a certain value of the semantic rapprochement coefficients with the words composing the input sentence. Several cases are possible, according to the speech context 
(realistic, funny, artistic, etc.) and according to the emotional states of both the child and the robot. The robot will then be able to answer the child either by keeping the same subject of discussion or a similar one, or by approaching another completely different subject.

Regarding this work, we planned for the possibility of corpus enrichment and the addition of new knowledge. So that, the system must be capable of semantically connecting the new words added to those which already exist in its knowledge database and to draw up their lists of properties.

\section{CONCLUSION}

Having successfully completed our studies on the face of the robot, his dynamics and the expression of his emotions, all of the rest still needs to be modeled. We, therefore, propose a model of emotion which is not based on the unique representation of simple emotional experiences.

Most of the work now is not only the association between these emotional experiences and keywords in the discourse but more importantly develop the process of generating emotions and behavior of the robot.

Our future work will focus on the development, as well as the evolution and the improvement of the mechanical robot to increase its functionality.

As for the cognitive interaction, we intend to make the system able to enrich its own vocabulary, and to define learning frameworks; according to the answers the system is going to produce, in order to adapt it to our expectations and to those of the children.

\section{ACKNOWLEDGMENT}

EmotiRob is currently financed by the regional council of Martinique, for the development of the emotional synthesis part, the regional council of Bretagne for the language comprehension part, and the ANR for the construction of the robot.

First of all, we would like to thank the regional council of Martinique, as well as the ANR for their collaboration.

The authors would like to thank Claire PALLARD, pediatrician, for her contribution for the realization of an evaluation grid.

The authors would like to thank members of the center of Kerpape (Laurence TRIVIERE, Marcelle SAMSON, Sylvie LEMONNIER and Annie BERTRAND) for their cooperation with our experiment.

The authors would also like to thank members of the IEA "Le Bondon" (Florence CHARPENTIER and Olivier THUAU) for their cooperation with our experiment.

The authors would like to thank Dominique Bassano for her corpus which allowed us to have such a complete tool on the vocabulary spoken by young children.

\section{REFERENCES}

[1] J. Villaneau, J-Y. Antoine and O. Ridoux : Logical Approach to Natural Understanding in a Spoken Dialogue System. In Proceedings of TSD, Brno, LNAI 3206, p.637-644, Czech Republic (2003).
[2] C. Blanche-Benveniste, «L'étude grammaticale des corpus de langue parlée en français », Journées linguistiques de corpus, 2002.

[3] E. Lambert, D. Chesnet. Novlex: une base de données lexicales pour les élèves de primaire. L'Année Psychologique, 2001, vol. 101, p. 277 288.

[4] B. Lété, L. Sprenger-Charolles, P. Colé. MANULEX : A grade-level lexical database from French elementary-school readers . Behavior Research Methods, Instruments, \& Computers, 2004, vol. 36, p. 156166.

[5] E. Boyle, A. H. Anderson, and A. Newlands." The Effects of Visibility on Dialogue in a Cooperative Problem Solving Task", Language and speech, vol. 37, 1994, p.1-20.

[6] http://paro.jp

[7] K. Wada, T. Shibata, T. Saito, K. Tanie. "Effects of Robot-Assisted activity for elderly people and nurse at day service center". In Proceedings of the IEEE, Vol. 92, No. 11, 2004, p. 1780-1788.

[8] T. Shibata. "An overview of Human Interactive Robots for psychological enrichment". In Proceedings of the IEEE, Vol. 92, No. 11, 2004, p. 1749-1758.

[9] P. Ekman, W. V. Friesen, J. C. Hager. "The facial action coding system”. Weidenfeld \& Nicholson, London, 2002.

[10] Jaffe database: http ://www.mis.atr.co.jp/ mlyons/jaffe.html

[11] A. Ortony, T. J Turner. "What's basic about basic emotions?" In Psychological Review. Vol. 97, 1990.

[12] C. Bartneck. "How convincing is Mr. Data Smile". In User Modeling and User-Adapted Interaction. Vol. 11, No. 4, 2001, p. 279-295.

[13] S. Saint-Aimé, B. Le Pévédic, D. Duhaut. Building emotions with 6 degrees of freedom. In Proceedings of SMC2007 - 2007 IEEE International Conference on Systems, Man, and Cybernetics, 7-10 October 2007, Montreal, Canada.

[14] R. S. Woodworth, H. Sclosberg. "Experimental psychology: Revised edition". Henry Holt, New York, 1954.

[15] A. W. Young, D. Rowland, A. J. Calder, N. L. Etcoff, A. Seth, D. I. Perrett. "Facial Expression Megamix: Tests of Dimensional and Category Accounts of Emotion Recognition". Cognition, vol. 63, 1997, p. 271-313.

[16] D. Watson, A. Tellegen. "Toward a consensual structure of mood". Psychological bulletin, vol. 98, p. 221, 1985.

[17] K. W. Fischer, P. R. Shaver, P. Carnochen. "How emotions develop and how they organize development". Cognition and emotion, vol. 4, 1990 , p. 81-127.

[18] http://www.redpsy.com/guide/, 2006

[19] D. Bassano, F. labrell, C. Champaud, F. Lemétayer, P. Bonnet. "Le DLPF: un nouvel outil pour l'éevaluation du développement du langage de production en français". Enfance, No. 2, 2005, p. 171-208.

[20] J. Piaget. "La représentation du monde chez l'enfant". Presses universitaires de France, 1947.

[21] J. Glass. "Challenges for spoken Dialogue Systems". In IEEE ASRU Workshop. KeyStone, Colorado, USA. 1999, p. 39-61.

[22] Y. Wilks, R. Catizone. "Encyclopedia of Microcomputers". HumanComputer Conversation. Dekker, New York, 2000.

[23] G. Gazdar. "The simulation of Human intelligence". The handling of natural language. Donald Broadbent edition. Blackwell, Oxford, 1993, p. $150-177$.

[24] http://www-valoria.univ-ubs.fr/emotirob/ 